\title{
An Impression Based Recording of Art Viewing Experience: Preliminary Implementation and Analysis
}

\author{
Takayuki Hoshino, Rentaro Yoshioka, and Masahiro Arai
}

\begin{abstract}
An implementation of a previously proposed method for expressing impressions of artwork is presented. The method employs sets of object-feeling pairs to describe impressions of artwork without relying on professional knowledge. The method is especially targeted for education of children as well as casual art fans. This work presents a practical implementation of the method with realistic format and symbol designs. Tests carried out with the implementation provide assuring results of the approach as well as insights into necessary improvements. Details of the implementation decisions and analysis of obtained results are reported.
\end{abstract}

Index Terms-Active knowledge, art viewing, multiple-view symbols, self-explanatory format, classification of features.

\section{INTRODUCTION}

Personal impression and communication play a key role in art education. For example, in interactive viewing methods, such as Visual Thinking Strategies [1], "subjective feeling" and "sharing and discussing individual feelings with others" is considered effective to further deepen one's learning [2]. For such activities, mutual vocabulary and procedure in expression and comprehension of person's feelings about the work is necessary. Currently, this is mostly done through spoken and written languages and relies greatly on language skills and individual vocabulary. One method to reduce the difficulty on part of the viewer is to apply the concept of Active Knowledge which allows to express impression of artwork without relying on special knowledge or vocabulary. Active Knowledge can be applied to art viewing by special software that supports expressing impressions of artwork by a variety of expression means other than conventional languages.

The basic approach for applying the concept of Active Knowledge for art education is discussed in [3]. The paper defines a classification of artwork features for building its multiple views, including viewer's impressions, in an Active Knowledge Format. The Active Knowledge Format functions as a self-explanatory format for circulating knowledge among different users through a create, explore, and donate cycle and supports incremental improvements by the involved users. More details of the format that is especially tailored for appreciation of art is discussed in [4]. In this work, the authors describe the syntax of combining element symbols to express impressions by object-feeling pairs including explicit composition syntax. Based on these work, the objective of

Manuscript received June 19, 2018; revised September 11, 2018.

The authors are with the Graduate School of Computer Science and Engineering, University of Aizu, Japan (e-mail: m5201204@u-aizu.ac.jp, m5201202@u-aizu.ac.jp, rentaro@u-aizu.ac.jp). this paper is to analyze and evaluate the practical feasibility of using Active Knowledge Format for artwork appreciation, especially on its ability to support and encourage expression of impressions.

In the following of this paper, related work is explained in section two, a brief overview of underlying concept and practical design are presented in section three, results of experiment are in section four, analysis of design based on experiment results is discussed in section five, and section six is conclusion.

\section{RELATED WORKS}

Museums around the world are taking advantage of technology to support and encourage art appreciation, represented by activities of major institutions such as The Metropolitan Museum of Art, Louvre Museum, Hermitage Museum, and Belvedere Art Museum, Cleveland Museum of Art as well as many others. The services provided by these museums through web pages and smartphone applications can be categorized into the following two types; 1) Browsing of artworks by author or various attributes, including title, creation year, exhibition place etc., 2) commentary of artwork including audio and video.

Google Arts \& Culture [5] is a service that allows users to freely search and refer to a huge image collection of over 1000 art museums in 70 countries around the world. The user of the service can search not only the work by the author or the theme but also the material and the technique of the work etc. In addition, users can also view works dynamically in 3D, such as arranging works by their characteristics, such as, age, category, and color tone.

The on-line version of Yokosuka Art Museum Art Card [6] provides a web service for art education. This service is based on a postcard-size "art card" on which a set of artworks are printed. The card is designed to stimulate interest and nurture the ability to observe artwork by playing games.

As such, existing services provided by museums assist browsing of artworks and related information prepared by the museum but do not provide services to express and share impressions.

In artwork appreciation, to stimulate one's artistic sensibility, it is considered effective to approach the artwork subjectively and to share and discuss that experience with others. However, to share and discuss your experience (often your impressions and emotions), it is necessary to express by means of words and sentences. This act of expression itself requires knowledge of vocabulary and good command of language and is an issue that hinders active expression and sharing by the ordinary person [7]. 
The treatment of subjective and emotional information such as feelings of artwork has been studied in the fields of subjective information processing and KANSEI information processing. In the fields of natural sciences and engineering, the objectivity of information is greatly emphasized, and in contrast, subjective information is considered as lacking universality (objectivity) and unappreciated [8]. Since the 1990s, inconveniences of excessive elimination of subjectivity has been recognized and fields, such as, subjective information processing and sensitivity information processing were born as methods for handling subjectivity appropriately. In these studies, written language is used for expression of subjective and emotional information and their results rely on correct understanding of words and sentences. In contrast, this research is based on a method that does not rely on literacy of written and spoken languages.

The method based on Active Knowledge applied in this paper is an initiative to support expression of impressions through symbols and format free from natural languages and is anticipated to become a new common expression to share individual, subjective experiences.

\section{METHOD}

The method of applying the concept of Active Knowledge to expression of artwork impressions is proposed in [3] and [4]. The objective of this research is to analyze and evaluate the practical feasibility of using Active Knowledge Format for artwork appreciation, especially on its ability to support and encourage expression of impressions. A focus is placed on investigating the balance between ease/precision of expressions verses format/symbol complexity.

TABLE I: CLASSIFICATION OF KNOWLEDGE FOR ARTWORK

\begin{tabular}{|l|l|l|}
\hline Feature Type & Element Type & Elements \\
\hline \multirow{2}{*}{ Explicit } & Basic & $\begin{array}{l}\text { title, artist name, year, } \\
\text { place of creation, size, } \\
\text { type, location, etc. }\end{array}$ \\
\cline { 2 - 3 } Implicit & Visual-object & $\begin{array}{l}\text { Shapes, colors, theme, } \\
\text { material, etc. }\end{array}$ \\
\hline & Feeling & $\begin{array}{l}\text { impression, emotion, } \\
\text { etc. }\end{array}$ \\
\hline
\end{tabular}

Based on previous work of [3], [4], [9], [10], the knowledge involved in artwork appreciation is categorized as Table I. As shown in the table, related knowledge is either an explicit feature or implicit feature. Explicit features are further classified into two element types "basic elements" and "visual elements". Basic elements include elements, such as, artwork titles, authors, and year of production and visual-object elements includes elements, such as, images, themes, and paintings of works. Implicit features are composed of feeling elements, such as, impressions and emotions. This classification is basically identical to that proposed in [3] but adds the notion of explicit/implicit for clearer characterization of features. For example, when a person views an artwork at a museum, the person would recognize the title and artist from a label posted besides it which corresponds to "basic elements" in the classification. Next, the person would view the artwork and observe the combination of shapes and colors which are "visual-object elements". Then the impressions and emotions that culminate in that person are the "feeling elements". The structural composition model of this knowledge set is depicted in Fig. 1. In the figure, relation of knowledge elements is defined as an entity-relation diagram. The core of the model is the "appreciation experience" which is composed of "artwork", "feeling", "viewer", and "appreciation environment". Appreciation environment is a type of basic element that explains the time, place, situation, etc. where the appreciation experience took place. It is distinguished from basic elements of artwork because viewing artwork at specific places or occasions can result in different experiences. An appreciation experience, in other words the impression resulting from viewing an artwork, is described by one or more "object-feeling pairs". An object-feeling pair is a combination of a "visual-object" and "feeling" where feeling is described by an "impression" and/or "emotion". The object-feeling pair is a new notion introduced in this paper that improves the model proposed in [4]. While the previous model required to identify a "target element" as one of a known type of object, our new model allows to specify the target anonymously. For example, to express that "the flower is beautiful", in the previous method, one would need to identify the flower and select the appropriate symbol from the category of botanical plants. In the new model, it is possible to point to the flower and simply express "this object is beautiful" (without identifying whether the object is a flower or not). This is useful for situations in which a person recognizes the color and shape but cannot clearly identify it (name it) as a known object.

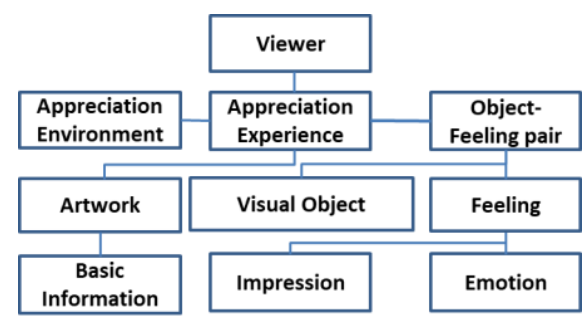

Fig. 1. Structural composition model for artwork appreciation.

The workflow for recording feelings has been proposed in [4]. In the proposed method, the viewer first selects an expression target, then associates impressions and emotions by selecting from a set of symbols. The viewer may create as many such associations for an artwork as appropriate, each corresponding to a specific part or feature. Impression and emotion symbols are prepared as Multi-view Symbols to express what the viewer felt without relying on natural language.

In this study, the workflow is slightly modified to aid analysis and evaluation. Also, as already described above, the appreciation model has been simplified compared to [4] by removing the composition of expressions (corresponds to "feeling" in this paper). In addition, words and icons are used instead of Multi-view Symbols for adjectives (corresponds to "impression" in this paper) and emotions, and color has been omitted. These simplifications were intended to simplify analysis of the effects of using the Active Knowledge model 
for actual artwork appreciation.

The workflow of the viewer in this analysis, depicted in Fig. 2 , is designed in respect to the model from cognitive psychology [10], [11]. In the figure, the three modes, (A) adversity, (B) belief, and (C) consequence, represent the basic process of human cognition and each of the artwork appreciation steps are aligned to them. First, the viewer faces the artwork (adversity). When viewing the artwork, the viewer would recognize various parts but the part that had the greatest impression on the viewer would be selected as the target (thus, target selection). Then the target would be "recognized" and an "impression" would be formed (belief). Finally, a reaction forms inside the viewer as an "emotion" and the appreciation is completed (consequence).

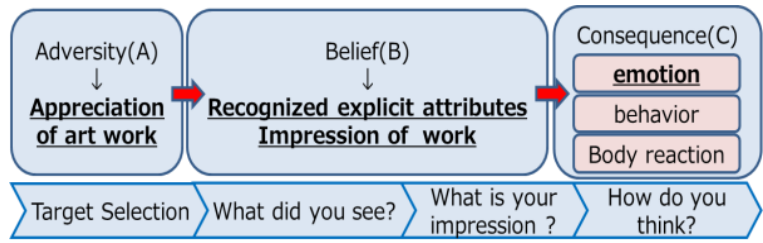

Fig. 2. Appreciation process model.

This workflow has been adopted in our implementation of the support software for artwork appreciation. The implementation details are described below.

To perform target selection, a viewer can select an area of interest by a procedure that mimics image cropping. The procedure is depicted in Fig. 3. In the figure, the viewer selects the area with the mouse, and then pushes the "Crop" button in (2). The selected area will be cropped and saved as in (3).

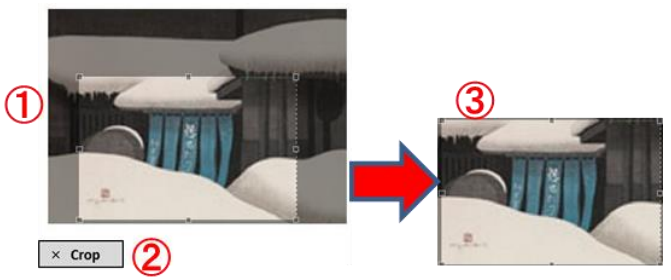

Fig. 3. Target selection by image cropping.

Expression of impression in this implementation is based on the method proposed in [4] but introduces a bilateral-scale to ease selection of subjective impressions. This design is consistent with the Semantic Differential Method used in many subjective evaluation measurements [12]. Also, adjective pairs reported in the painting impression study is adopted for expressing impressions using bipolar-scales [13]. According to the study, impression of a painting is constituted by four components "evaluation", "activity", "brightness", and "softness", each of which are represented by four adjective pairs as listed in Table II. In the table, icon images used to provide further hints for each category and adjective pairs are also shown. Note that each word is represented in both Japanese and English since this study was performed to Japanese users.

For the symbols for emotions, the classification of Plutchik's eight basic emotions [14], which is also adopted in [3], [4], [9] is used. The eight basic emotions along with corresponding icon images are listed in Table III. The table also includes corresponding emotional adjectives that are displayed to viewers for clarification but only the basic emotions are distinguished.

TABLE II: IMPRESSION ADJECTIVES

\begin{tabular}{|c|c|c|c|c|c|}
\hline \multicolumn{2}{|l|}{ Category } & \multicolumn{2}{|l|}{ Scale1 } & \multicolumn{2}{|l|}{ Scale2 } \\
\hline Name & Icon & Adjective1 & Icon & Adjective2 & Icon \\
\hline \multirow{4}{*}{$\begin{array}{l}\text { 㲕価 } \\
\text { (Evaluation) }\end{array}$} & \multirow{4}{*}{ 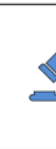 } & 良い(Good) & 15 & 亜い(Bad) & ו \\
\hline & & 美しい(Beautiful) & $\Delta$ & 酮い(Ugly) & $\omega$ \\
\hline & & 好き(Likable) & $\bullet$ & 嫌い(Unlikable) & $\theta$ \\
\hline & & 快い(Pleasant) & 为 & 不快な (Unpleasant) & 8 \\
\hline \multirow{4}{*}{$\begin{array}{l}\text { 翟動感 } \\
\text { (Activity) }\end{array}$} & \multirow{4}{*}{$\mathcal{I}$} & 動的 (Dynamic) & $y_{1}$ & 静的 (Static) & 으 \\
\hline & & 不安定な(Unstable) & 2000 & 安定した(Stable) & - \\
\hline & & 個性的な(Original) & 5 & 平凡な(Common) & 尌 \\
\hline & & 派手な(Showy) & 89 & 地味な(Sober) & $\approx$ \\
\hline \multirow{4}{*}{$\begin{array}{l}\text { 明るさ } \\
\text { (Brightness) }\end{array}$} & & 明るい(Bright) & $r^{11}$ & 暗い(Dark) & $\hbar_{*}$ \\
\hline & & 陽気な(Cheerful) & 2 & 陰気な(Gloomy) & 80 \\
\hline & & 暖かい(Warm) & 28 & 冷たい(Cold) & (h) \\
\hline & & 楽しい(Fun) & 视 & 叔しい(Lonely) & (2) \\
\hline \multirow{4}{*}{$\begin{array}{l}\text { やわらかさ } \\
\text { (Softness) }\end{array}$} & \multirow{4}{*}{7} & Фるんだ(Loose) & 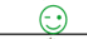 & 緊張した(Strained) & 8 \\
\hline & & くつろいだ(Relaxed) & 诳 & 張り詰めた(Tense) & 2 \\
\hline & & 楾やかな(Calm) & ithis & 粠格な(Strict) & (1) \\
\hline & & 柔らかな(Soft) & 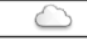 & 固い(Hard) & $\stackrel{9}{*}$ \\
\hline
\end{tabular}

TABLE III: EMOTION SYMBOLS

\begin{tabular}{|c|c|c|c|c|c|}
\hline Basic & Relevant & ICON & Basic & Relevant & ICON \\
\hline \multirow[t]{2}{*}{$\begin{array}{l}\text { 期待 } \\
\text { (Anticipation) }\end{array}$} & $\begin{array}{l}\text { 関心 } \\
\text { (Interest) }\end{array}$ & & \multirow[t]{2}{*}{\begin{tabular}{|l} 
驚き \\
(Surprise)
\end{tabular}} & $\begin{array}{l}\text { 動摇 } \\
\text { (Distraction) }\end{array}$ & \\
\hline & $\begin{array}{l}\text { 警戒 } \\
\text { (Vigilance) }\end{array}$ & & & $\begin{array}{l}\text { 驚愕 } \\
\text { (Amazement) }\end{array}$ & \\
\hline \multirow[t]{2}{*}{$\begin{array}{l}\text { 喜び } \\
\text { (Joy) }\end{array}$} & $\begin{array}{l}\text { 安らぎ } \\
\text { (Serenity) }\end{array}$ & & \multirow[t]{2}{*}{$\begin{array}{l}\text { 悲しみ } \\
\text { (Sadness) }\end{array}$} & $\begin{array}{l}\text { 哀愁 } \\
\text { (Pensiveness) }\end{array}$ & \\
\hline & $\begin{array}{l}\text { 恍惚 } \\
\text { (Ecstasy) }\end{array}$ & & & $\begin{array}{l}\text { 悲嘆 } \\
\text { (Grief) }\end{array}$ & \\
\hline \multirow[t]{2}{*}{$\begin{array}{l}\text { 信頼 } \\
\text { (Trust) }\end{array}$} & $\begin{array}{l}\text { 容認 } \\
\text { (Acceptance) }\end{array}$ & & \multirow[t]{2}{*}{$\begin{array}{l}\text { 嫌悪 } \\
\text { (Disgust) }\end{array}$} & $\begin{array}{l}\text { 倦急 } \\
\text { (Boredom) }\end{array}$ & \\
\hline & $\begin{array}{l}\text { 敬愛 } \\
\text { (Admiration) }\end{array}$ & & & $\begin{array}{l}\text { 憎悪 } \\
\text { (Loathing) }\end{array}$ & \\
\hline \multirow[t]{2}{*}{$\begin{array}{l}\text { 心配 } \\
\text { (Fear) }\end{array}$} & $\begin{array}{l}\text { 不安 } \\
\text { (Apprehension) }\end{array}$ & & \multirow[t]{2}{*}{$\begin{array}{l}\text { 怒り } \\
\text { (Anger) }\end{array}$} & $\begin{array}{l}\text { 苛立ち } \\
\text { (Annoyance) }\end{array}$ & \\
\hline & $\begin{array}{l}\text { 恐怖 } \\
\text { (Terror) }\end{array}$ & & & $\begin{array}{l}\text { 激怒 } \\
\text { (Rage) }\end{array}$ & \\
\hline
\end{tabular}

An image of the user interface to input object-feeling pairs is shown in Fig. 4. According to the viewing process model described above, input is carried out from the left, 1) target selection by cropping, 2) selection of impression using the bipolar scale per adjective pair, and 3) selection of one of eight emotions.

For the study, subjects were asked to fill-out a questionnaire after the experiment. The questionnaire covered the following content.

- Ease of the input procedure

- Intuitiveness and satisfaction of impression expression

\section{RESULT}

As shown in Table IV, there were 22 subjects in the preliminary experiments with ages from 20 to 60 . The subjects' experience on artwork appreciation activities was measured by two questions as listed in Table V. The subjects were asked to select from three levels "high", "neither", and "low". As shown in the table, most of the subjects had some interest in viewing artwork but showed varying frequencies of actual artwork viewing. The results of the responses to qualitative questions of the survey are shown in Table VI. 
印象に残つた部分をマウスで切り取つてみましょう。 Crop put the part left in the impression.

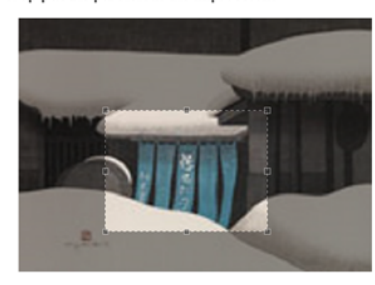
$\times$ Crop

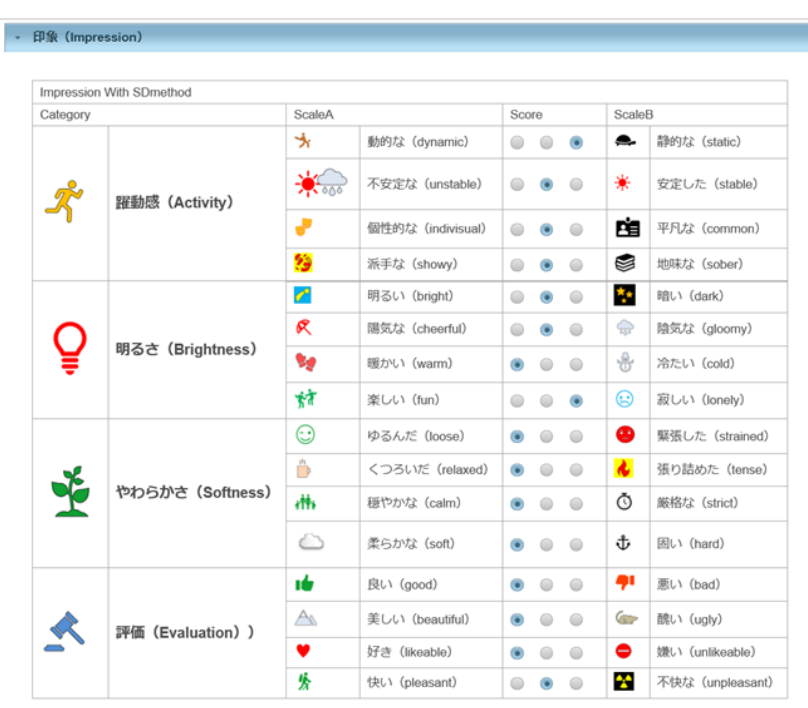

3)How do you think?

Fig. 4. User interface to input object-feeling pairs.

TABLE IV: PROFILE OF SUBJECTS

\begin{tabular}{|l|r|r|r|r|r|}
\hline Age & \multicolumn{1}{|c|}{20 's } & \multicolumn{1}{c|}{30 's } & \multicolumn{1}{c|}{40 's } & \multicolumn{1}{c|}{50 's } & \multicolumn{1}{c|}{$60+$} \\
\hline Number of subjects & 5 & 4 & 4 & 8 & 1 \\
\hline
\end{tabular}

TABLE V: EXPERIENCE IN ART VIEWING

\begin{tabular}{|l|r|r|r|}
\hline & \multicolumn{1}{|c|}{ High } & Neither & Low \\
\hline Interested in art viewing & 10 & 9 & 3 \\
\hline Frequency of art viewing & 7 & 6 & 9 \\
\hline
\end{tabular}

TABLE VI: EVALUATION OF INPUT METHOD

\begin{tabular}{|l|r|r|r|}
\hline & \multicolumn{1}{|c|}{ High } & Neither & Low \\
\hline Ease of input & 21 & 1 & 0 \\
\hline $\begin{array}{l}\text { Satisfaction of } \\
\text { expression }\end{array}$ & 17 & 3 & 2 \\
\hline Effort of input & 14 & 7 & 1 \\
\hline Ease of target selection & 16 & 5 & 1 \\
\hline $\begin{array}{l}\text { Intuitiveness of selecting } \\
\text { impression }\end{array}$ & 14 & 7 & \\
\hline
\end{tabular}

TABLE VII: NOTABLE COMMENTS ON INPUT PROCEDURE

\begin{tabular}{|l|l|}
\hline Step & \multicolumn{1}{c|}{ User Comment } \\
\hline Target Selection & $\begin{array}{l}\text { Since you can cut-out directly from image, it } \\
\text { is intuitive and easy to express. } \\
\text { It is better to be able to select multiple targets } \\
\text { since there can be more than one impression } \\
\text { from each artwork. }\end{array}$ \\
\hline Selection of Impression & $\begin{array}{l}\text { Selecting an appropriate value from the } \\
\text { bipolar-scale of adjective pairs that best } \\
\text { matches my feeling was difficult. }\end{array}$ \\
\hline Selection of Emotion & $\begin{array}{l}\text { It was difficult to relate the "words" in the } \\
\text { options to actual feelings. The operation } \\
\text { should also be more intuitive. }\end{array}$ \\
\hline
\end{tabular}

For a better illustration of user responses, notable free-style comments of users are shown in Table VII. Samples of actual object-feeling pairs created by two subjects are show in Fig. 5 . In the figure, $A$ is an object-feeling pair created by one subject and $B$ is that of another subject. In each object-feeling pair, the set of target artwork, visual object, impression, and emotion selected by the user are shown.
Both samples are for the same artwork with the title “会津 の冬(75)喜多方 / Winter in Aizu (75) Kitakata” [15]. A picture of the original artwork is shown at the top as "Target Artwork". Below that is a cropped image created by the subject and labeled "Visual Object". The subjects of both samples selected similar areas, the entrance of a shop with the blue draping. Note the slight difference in size and shape of cropped area, a characteristic of direct operations. In the row for "Impression", results of subject's selection of four impression categories are shown. For sample A, looking at the activity category, the subject felt more "static" on the dynamics-scale and more "common" on the originality -scale. The subject had neutral impressions on the stability- and showy-scales. Similarly, the subject felt "gloomy" for cheerfulness and "soft" for softness and "pleasant" for pleasantness-scales. Finally, in the "Emotion" row, the emotion of the artwork selected by the subject is "joy".

\section{DISCUSSION}

Based on actual subject tests using the preliminary implementation and corresponding results from questionnaires, our proposed method was evaluated for ease of input procedure and the intuitiveness/satisfaction of impression expression.

In response to the questionnaire, most of the users (95\%) evaluated the procedure as "easy to understand". Regarding expression of impressions, majority of users $(75 \%)$ were satisfied with the results. Overall, the positive reception by users is assuring that this style of expressing impressions of artwork is widely acceptable through a varying range of age and familiarity with artwork appreciation.

Looking more closely at the results in Table VI the evaluation of "effort of input" and "intuitiveness of selecting impression" are scattered among "high" and "neither" showing that not all were happy with the operations. 

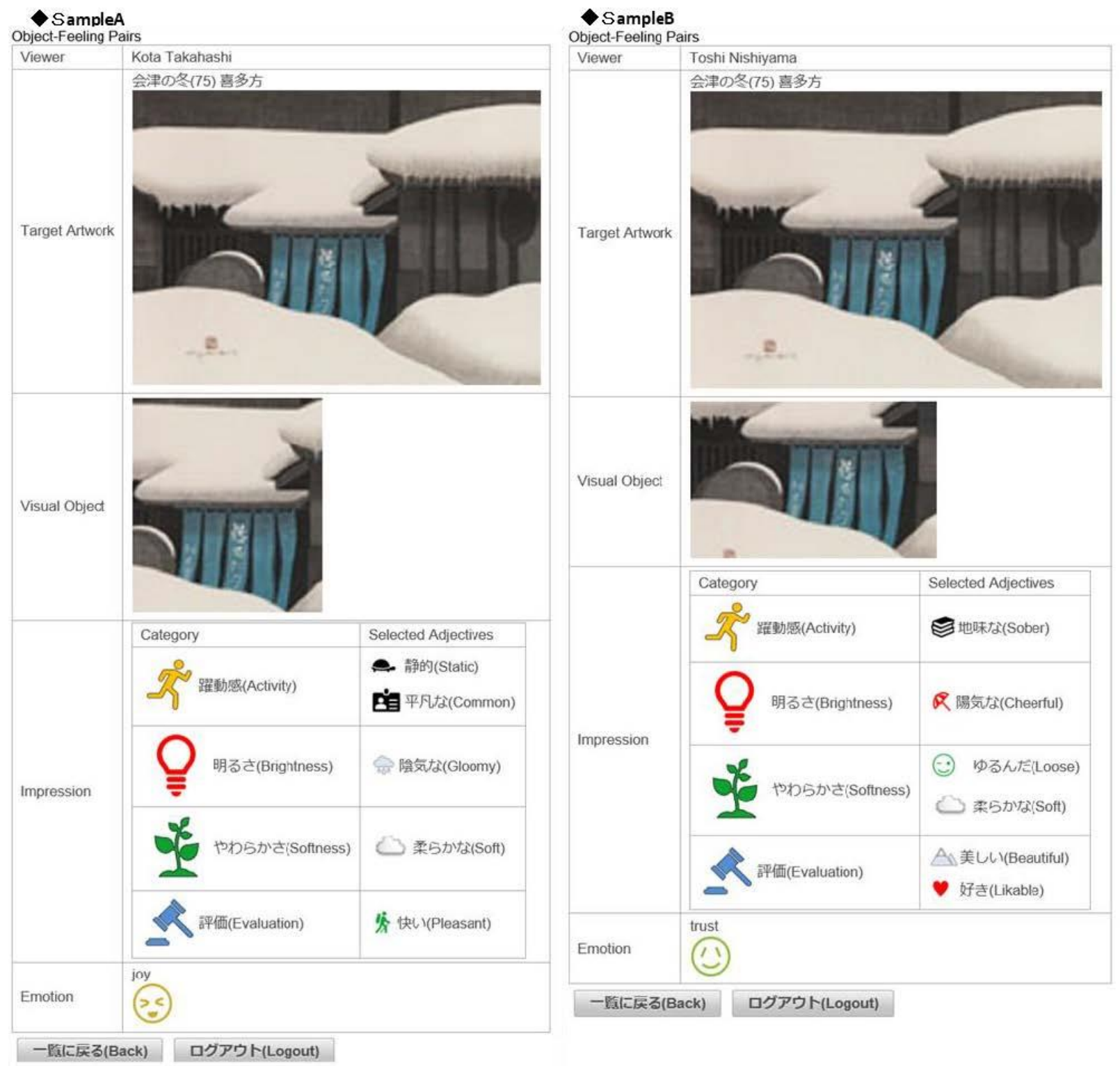

Fig. 5. Samples of object-feeling pairs.

The background of these responses could be speculated from comments expressed in free text (show in Table VII). A comment related to target selection mentions the difficulty of selecting only one area of interest. Also, a comment related to selection of impressions indicates the difficulty of deciding a value between two opposite adjectives to match own feeling. Moreover, a comment on selection of emotion point out the difficulty of matching a word from the choices to their emotion. All these difficulties may have two sides. One side of the difficulty is related to the functional aspect of the interface and another side is related to the fundamental aspects of making decisions on one's impressions and emotion. The former is an issue that could be improved with better symbols (relative to adjective words) which is a work in progress in our group as "Multiple-view symbols" (see [3], [4], [9]). The latter is an issue that could be improved by the process of selection that would support the user's decision making and ease the sense of difficulty. This is necessary considerations for future work.

Apart from the overall positive results, a question on how to reflect one object-feeling pair with the total impression of artwork has yet to be solved. Each object-feeling pair is considered as "partial impressions". It is natural that a person would notice several targets of impression for a given artwork. In such case, the partial impressions must be accumulated in to a "total impression". This gives rise to further questions on relative strengths of impressions and how "summation" of impressions work. These are interesting directions for the next step.

\section{CONCLUSION}

A practical implementation of an Active Knowledge interface to assist artwork appreciation was described and analyzed. The implementation focused on evaluation of the features supported by the expression format as well as the understandability of expression symbols. From the analysis and evaluation of preliminary experiments, the following two points were confirmed.

As the first point, the proposed Active Knowledge model was generally accepted by users. Secondly, the expression of impressions and emotions using words (adjective and nouns) was not as straight forward as expected to some users.

These findings were inline with our expectations and 
encouraging for our on-going work to fully implement Multi-view Symbols for impressions and emotions to reduce or eliminate reliance on words. Also, necessity of additional consideration on how multiple object-feeling pairs contribute to the total appreciation experience is required, including a suitable algorithm to aggregate the individual experiences.

\section{REFERENCES}

[1] P. Yenawine, Visual Thinking Strategies, Harvard Education Press, 2013.

[2] H. Kitamura, "Significance and practice of the art viewing education," M.S. thesis, Graduate School of Policy and Management, Doushisha University, 2016.

[3] K. Igarashi, S. Seino, and R. Yoshioka, "An active knowledge service for art education," in Proc. the International Technology, Education \& Development Conference, INTED2015, March 2015, pp. 4636-4644.

[4] D. Hashimoto, "Symbols and format for self-explanatory specification of feelings," M.S. thesis, University of Aizu, March 2016.

[5] Google Arts \& Culture. [Online]. Available: https://www.google.com/culturalinstitute/beta/

[6] Yokosuka Museum Art Card Web-Version, [Online]. Available: http://yokosuka.artcard.info/

[7] N. Kaya, "A study on the effect of language and co-imagination on art appreciation activity," Journal of the Japan Society for Art Education, vol. 299, pp. 8-14, 2015.

[8] A. Yoshikawa, "Sensitivity information processing and subjectivity information processing," Computer Today, vol. 15, no. 1, pp. 34-39, 1998.

[9] H. Sawai and R. Yoshioka, "An interface to elicit and express people's experience: For visit to places," in Proc. the International Technology, Education \& Development Conference, INTED2016, March 2016, pp. 1329-1336.

[10] S. Markovic and A. Randonjic, "Implicit and explicit features of paintings," Spatial Vision, vol. 21, pp. 229-259, 2008.

[11] A. Ellis, "Expanding the ABCs of RET," Journal of Rational Emotive Therapy, Cognition and Psychotherapy, pp. 20-24, September 1984.

[12] C. Osgood, G. Suci, and P. Tannenbaum, The Measurement of Meaning, University of Illinois Press, 1957.

[13] K. Cho and M. Haraguchi, "Scale construction of adjective pairs on the research of impression of paintings," Kurume University Psycological Reaserch, pp. 45-53, 2014.
[14] R. Plutchik and H. Kellerman, Emotion: Theory, Research and Experience (Vol. 3), New York Academic Press, 1986.

[15] Yanaizu. Kiyoshi Saito Museum of Art. [Online]. Available: https://www.town.yanaizu.fukushima.jp/bijutsu/store/img_large/postc ard/800px_117.jpg

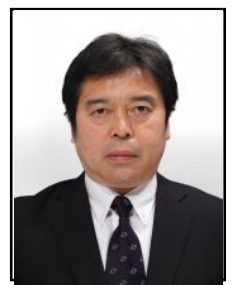

Takayuki Hoshino is currently studying at the Graduate School of Computer Science and Engineering in the University of Aizu as a student of social studies.

He joined Nihon Unisys Corporation in 1985. After technical education department, data analysis technology department, consigned system development department, since 2006, he is a senior researcher at the company's general technical research institute. He is interested in knowledge formation from experience.

Mr. Hosihno is a member of Project Management Association of Japan ( PMAJ).

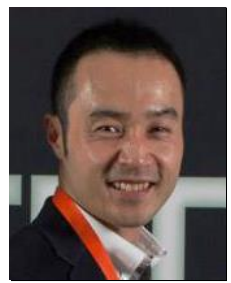

Rentaro Yoshioka received the BA in physics from the College of Liberal Arts, International Christian University, Tokyo, Japan in 1996. He received his MS (1999) and $\mathrm{PhD}$ (2002) in computer science and engineering from the University of Aizu, Fukushima, Japan. He is currently senior associate professor in the Active Knowledge Engineering Laboratory at the Graduate School of Computer Science and Engineering, University of Aizu. He has been working on user-centered programming languages/environments, programming learning tools, software engineering and 3DKanji. Currently, his research focus is on active knowledge engineering, especially on new formats for knowledge creation/communication, and practical approaches for software engineering education.

Prof. Yoshioka is a member of ACM and IEEE.

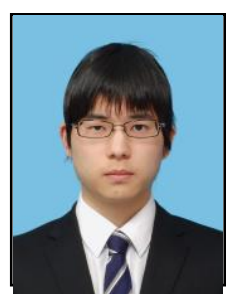

Masahiro Arai graduated from Division Information Systems in the Faculty of Computer Science an Engineering, University of Aizu in 2016. He is currently studying at the Graduate School of Computer Science and Engineering, Graduate School of Engineering. He is interested in support of knowledge utilization by information system. 